\title{
Enlisting Aero-algal Flora and Algal Allergens Using Fan Dust Sampling Method from Pune, Maharashtra
}

\author{
Apurva Kapil Kamble and Jogita Tushar Pandkar* \\ Department of Botany, Fergusson College (Autonomous), Pune, Affiliated to \\ Savitribai Phule Pune University- 411004 (Maharashtra), India. \\ http://dx.doi.org/10.13005/bbra/2958
}

(Received: 14 October 2021; accepted: 21 December 2021)

\begin{abstract}
Algae in the atmosphere are one of the bio-components of the environment. Despite the fact that they may have a negative impact on human health, they are the least studied organism in the field of aerobiology. Airborne algae continue to be viable in the atmosphere in the form of spores and filaments. In order to investigate the intramural diversity of airborne algae in Pune, eight residences were chosen, from which 16 fan dust samples were collected over a ten-day period. Total (108) aero-algal forms were recorded. Out of which 107 were Cyanophyta, and only one was Chlorophyta. The dominance of Cyanophyta members is attributed to the presence of a thick mucilaginous sheath around them, which allows them to tolerate the dryness. Overall, filamentous cyanophytes (71) outnumber coccoid cyanophytes (36). However, both fan dust slide samples and culture slide samples show variance. Coccoid cyanophytes (53) outnumber filamentous cyanophytes (11) in direct slide scans, although filamentous cyanophytes (25) were somewhat more numerous in culture samples than coccoid Cyanophyta (19). This increase in filamentous forms might be because of hormogonia of filamentous algae, which remained unidentified in direct slide scan and upon inoculation underwent reproduction increasing number of filamentous algae in culture slides. Chrooccocus, Gloeocapsa, Lyngbya, Nostoc, and Stigonema were among the forms found on the first and tenth days of fan dust sampling, indicating that they were a common inhabitant of fan dust during the study and that the fan, as an aero sampler, was able to capture them, demonstrating its potency as an aero sampler. Soil can be a substantial factor in the creation of fan dust, as these genera were frequently separated from the soil. Gloeocapsa, Phormidium, Lyngbya, Schizothrix, Cylindrospermum, Nostoc, Anabaena, Scytonema, Calothrix, and Scenedesmus were among the allergic aero-algal genera discovered during the investigation.
\end{abstract}

Keywords: Aero-Algae; Allergenic Aero-Algae; Cyanophyta; Fan As An Aero Sampler; Intramural Aero Sampling.

Dust is omani present and found on different objects like tables, bookshelf, beds, floors etc. Bacteria, protozoa, fungus, pollen grain, and other organisms were discovered in dust from diverse locations. One of its most essential components was microalgae. Ehrenberg (1844) ${ }^{1}$ was the first to report viable algae derived from sea dust. Since then, scientists have experimented with a variety of techniques to capture dust from various locations. Pandkar $(2011)^{2}$ classified a few of these approaches.

Luty et al. (1964) investigate aerospora in the Santa Catalina Mountains and the Tucson area at various heights. At San Antonia, Texas, 
Fulton et al. (1966) ${ }^{4}$ used aircraft to collect air samples. Harold E. Schlichting, Jr. (1971) $)^{5}$ studied algae and protozoa using seafoam as a sample. Burge et al. (1982) ${ }^{6}$ investigated indoor allergens using a battery-powered rotarod sampler. Lee et al. (1989) ${ }^{7}$ successfully trapped marine cyanobacteria in an air sample. Ahmed D.Gamal $(2008)^{8}$ employed the Petri plate exposure method in Cairo and discovered Nostoc spp. as a common isolate. Nuhu and Ahmad (2008) ${ }^{9}$ in Saudi Arabia employed biofilm from the cooling pad of a greenhouse evaporative cooling system to evaluate cyanobacteria fouling. In their review article, Stephen Ambu et al. (2011)10 examined indoor air quality and building-related sickness in Malaysia. E.Hui-Ping Ng et al. (2011) ${ }^{11}$ conducted the first-ever outdoor survey at Bukit Jalil in Kuala Lumpur to investigate the distribution of airborne algae, while an indoor survey was conducted to investigate the occurrence of airborne algae and cyanobacteria in an intramural environment of a Kuala Lumpur office building by W-L. Chu et al. $(2013)^{12}$. Sylvie V.M.Tesson et al. (2016) ${ }^{13}$ explored step-by-step dispersal of aero algae in a minireview. The influence of heat events on atmospheric bacterial communities was studied by Zhiguo Fang et al. $(2018)^{14}$ using a Coriolis air sampler.

N.K.Sharma et al. $(2006)^{15}$ investigated air, water, and soil samples and discovered that algae react differently to climate variations, resulting in seasonal variance. N.K.Sharma et al. $(2006)^{16}$ used a tilak rotarod sampler and a Petri plate exposure method to record thirty-four airborne algae in which Cyanophyta was found to be prevalent at the height of 2.5 metres. N.K.Sharma et al. $(2011)^{17}$ suggested that the abundance of terrestrial algae in the atmosphere could be due to their adaptation to dryness. Dubey et al. (2010) ${ }^{18}$ collected 12 allergenic airborne algae from Kanpur wetlands using a gravity slide sampler and a Petri plate exposure method. In rural Kanpur, Verma et al. (2011) ${ }^{19}$ employed the Petri plate exposure approach to identify Cyanophyta as the major group. D.S.Seetharam et al. $(2015)^{20},(2016)^{21}$ employed spider web as samples to research aerospora at Sanjeevaiah Park Hyderabad and Pakhal Wildlife Sanctuary Warangal, respectively. In a review study, N.K.Sharma et al. (2006) ${ }^{22}$ and Nivediata Sahu et al. (2014) ${ }^{23}$ discussed the occurrence of airborne algae, their distribution, and numerous meteorological parameters that affect them.

Pandkar $(2010)^{24}$ conducted aero sampling with a rotarod sampler at Nagpur's vegetable and fish market, revealing the dominance of Cyanophyta members. Milind Jadhav et al. $(2010)^{25}$ and Sunita Jawale et al. (2017) ${ }^{26}$ used the Petri plate exposure method to investigate the aero algae of Aurangabad. A miniature Lakhanpal and Nair aero sampler was mounted on the mudguard of a Vespa scooter by (Pandkar 2011) ${ }^{27}$ to determine the presence of allergenic algae at human breathing level in Nagpur. Chougule et al. $(2016)^{28}$ collected house dust from patients with nasobronchial allergies and discovered that Cyanophyta was the most common isolate in those homes.

Balkrishna and Gunale $(1980)^{29}$ published the first study on the occurrence of airborne algae in Pune's environment. Pandkar $(2010)^{30}$ conducted extramural rotarod sampling in Pune and found Cyanophyta to be the dominant group. V.S. Patil et al. (2014) $)^{31}$ employed the Petri plate exposure method to identify 24 algal allergens in the Pune atmosphere. Pandkar $(2011,2017)^{2,32}$ made the first attempt to employ the fan as an aero sampler in Nagpur and Guhagar. However, there were no reports on intramural air sampling, except for a few extramural reports from Pune. As a result, this research was carried out to investigate intramural aero algae employing the fan as an aero sampler.

For this investigation, the fan was employed as an aero sampler to collect samples from eight homes in and around Pune. The study focuses on a preliminary survey to validate the existence of aero algae in fan dust samples, the source of the algae, and the algal flora acquired, and to report allergic aero algae from fan dust samples collected.

\section{MATERIAL AND METHOD}

Despite the numerous types of samplers listed above, an affordable, adaptable sampler is always required for fundamental qualitative analysis. One or more ceiling fans can be found in any home, workplace, or institution. Because of the electrostatic charge created on the fan blades due to friction with air, a thick coat of airborne dust collects on the edges of fan blades as they revolve. The first layer of dust absorbs moisture from the air, 
increasing their ability to capture more air particles and resulting in a thicker dust coat on the fan blades. Furthermore, because these fans are primarily out of human reach, they collect only dust from the air and are less susceptible to contamination. Given that fan was employed as a sampler in the current investigation, a novel strategy in aerobiological research is rarely undertaken.

From March to June 2019, 16 samples were gathered utilising a fan as a sampler in and around Pune. Initially, dust was collected from the fan's blades with the help of a spatula and stored in a clean zip lock bag. After collecting fan dust, the blades of the fan were cleaned using a soap solution and then a clean towel. For the next ten days, the fan was used in the usual manner. The dust was scraped from the edges of fan blades using a spatula on the tenth day and placed in a clean zip lock bag. Fan dust collected was processed by following two methods,

\section{Fan Dust Culture Preparation}

Samples in zip lock bags were then bought to the laboratory; some of the dust from samples collected from the fan was inoculated in sterile B.G.11 media and was incubated naturally. Growth starts to appear after a month. Upon optimum growth, the slide was prepared using glycerin as mounting media.

\section{Direct Fan Dust Slide Preparation}

The remaining samples were utilised to prepare direct fan dust slides. These fan dust samples were macerated with dilute $\mathrm{HCl}$ to dissolve dust calcium and magnesium carbonates. The remaining acid was washed well with sterile D/W using a centrifuge (Pandkar 2011, Pandkar 2017) ${ }^{2,32}$. Few drops from the supernatant were mounted on the centre of a clean glass slide with glycerin as mounting media. The slide was then covered with a $22 \times 60 \mathrm{~mm}$ coverslip and sealed with nail polish. Slides prepared were further identified and microphotographed. The identification of algae was done by using standard available literature. (Desikacharya, 1959; Prescott, 1954) ) $^{33,34}$

Media and Instrumentation Used for Study

1. Culture media - B.G. 11 broth with minerals, M1958-500G (H.I.M.E.D.I.A., Lot\# 0000314677).

2. Centrifuge - B.E.X.O. tabletop centrifuge

3. Microscope - LM5209

4. Camera - LM1918 CMOS

All other reagents used were of lab grade.

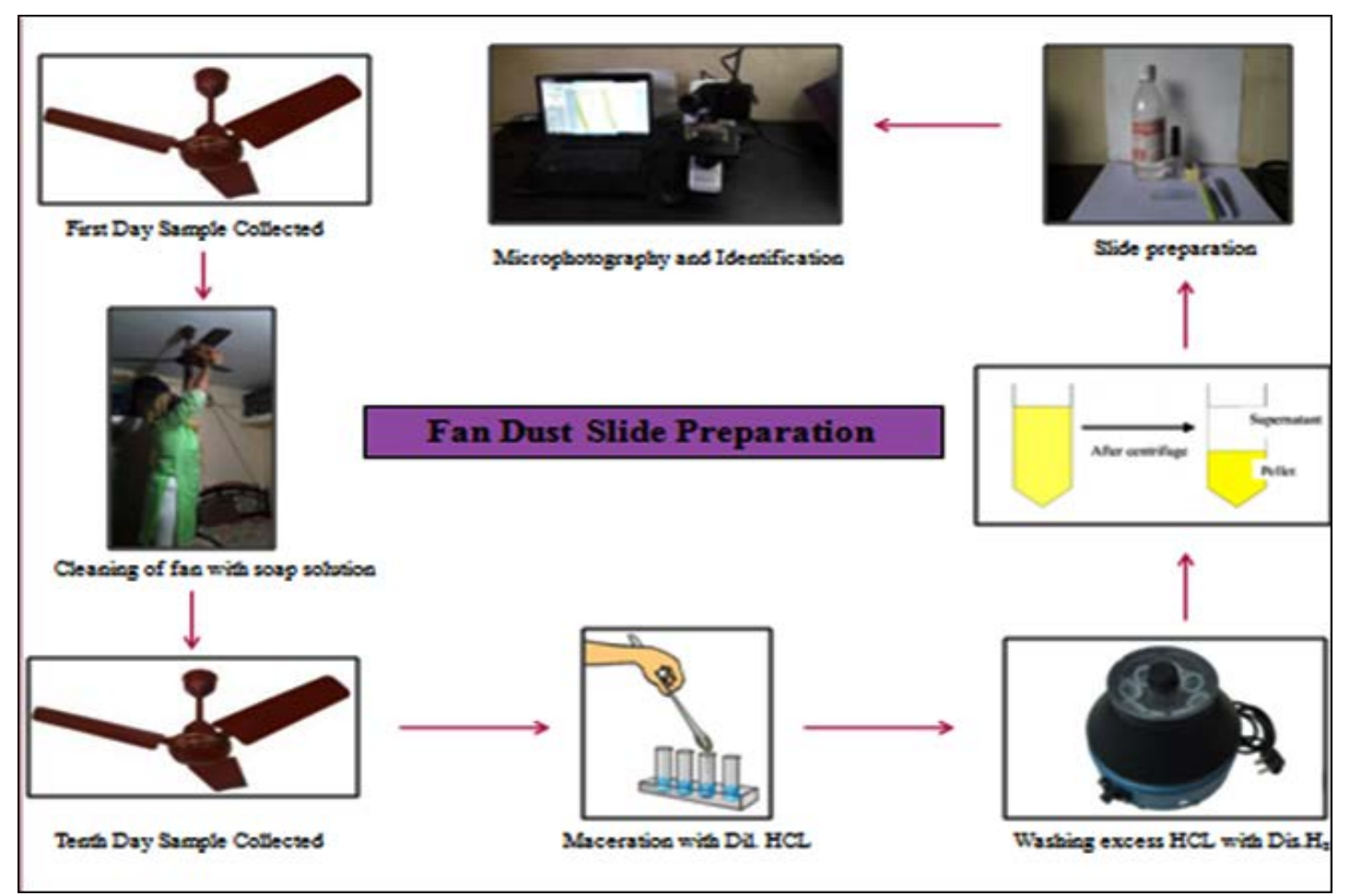

Fig. 1. Direct Fan Dust Slide Preparation and Scanning Method 


\section{RESULT AND DISCUSSION}

Two methods processed total 16 fan dust samples collected from in and around Pune,

1. Direct Fan Dust Slide Preparation,

2. Fan Dust Culture Slide Preparation.

Cumulatively 108 algal forms were recorded. Out of (108) aero-algal forms recorded, (63) were identified up to class level, (19) up to genera level and (26) up to species level, respectively (Table 1 and Table 2). Out of 108 algal forms, 107 were Cyanophytes pointing towards its supremacy in the indoor environment of Pune. Similar results were obtained by Gunale $(1980)^{29}$, Pandkar $(2011)^{2}$, and Patil V.S et al. (2014) ${ }^{31}$ in the extramural environment of Pune. Scenedesmus was the only Chlorophyta member found during the present study. A recent study carried out by Pandkar et al. $(2020)^{35}$ at Fergusson College Pune in which samples were collected from various habitats shows Cyanophyta's dominance with the scarce presence of Chlorophyta followed Bacillariophyta.

Cyanophyta members were further divided into Cyanophyta filamentous and Cyanophyta coccoid types. Coccoid cyanophytes (53) were shown to be dominant over filamentous cyanophytes (11) in direct slide scanning, although filamentous cyanophytes (25) were marginally more numerous than coccoid (19) cyanophytes in culture samples (Graph I and Graph II). This discrepancy could be attributed to the fact that coccoid cyanophytes were in a vegetative stage or that the spore forms were not viable. In addition, coccoid cyanophytes could easily be swept away by the wind due to their circular form and lightweight. As a result, their quantity was high in direct slides of fan dust samples. On the other hand, hormogonia might be found as tiny particles in direct fan dust that remain unidentified in direct fan dust slide proliferated after being inoculated in culture media, increasing the number of filamentous algae in culture samples. It specifies that sampling should be followed by culture, which will aid in the study of latent viable spores, which are difficult to see during slide scanning.

Generic diversity obtained from culture reveals diverse aero algal filamentous cyanophytes compared to coccoid cyanophytes. In culture samples, genus Nostoc (11) was dominant with Nostoc punctiforme recorded from (7) samples followed by Nostoc verrucosum, Nostoc muscorum, and Nostoc ellipsosporum recorded from (1) sample each. It was followed by Stigonema (3) with Stigonema hormides and Stigonema

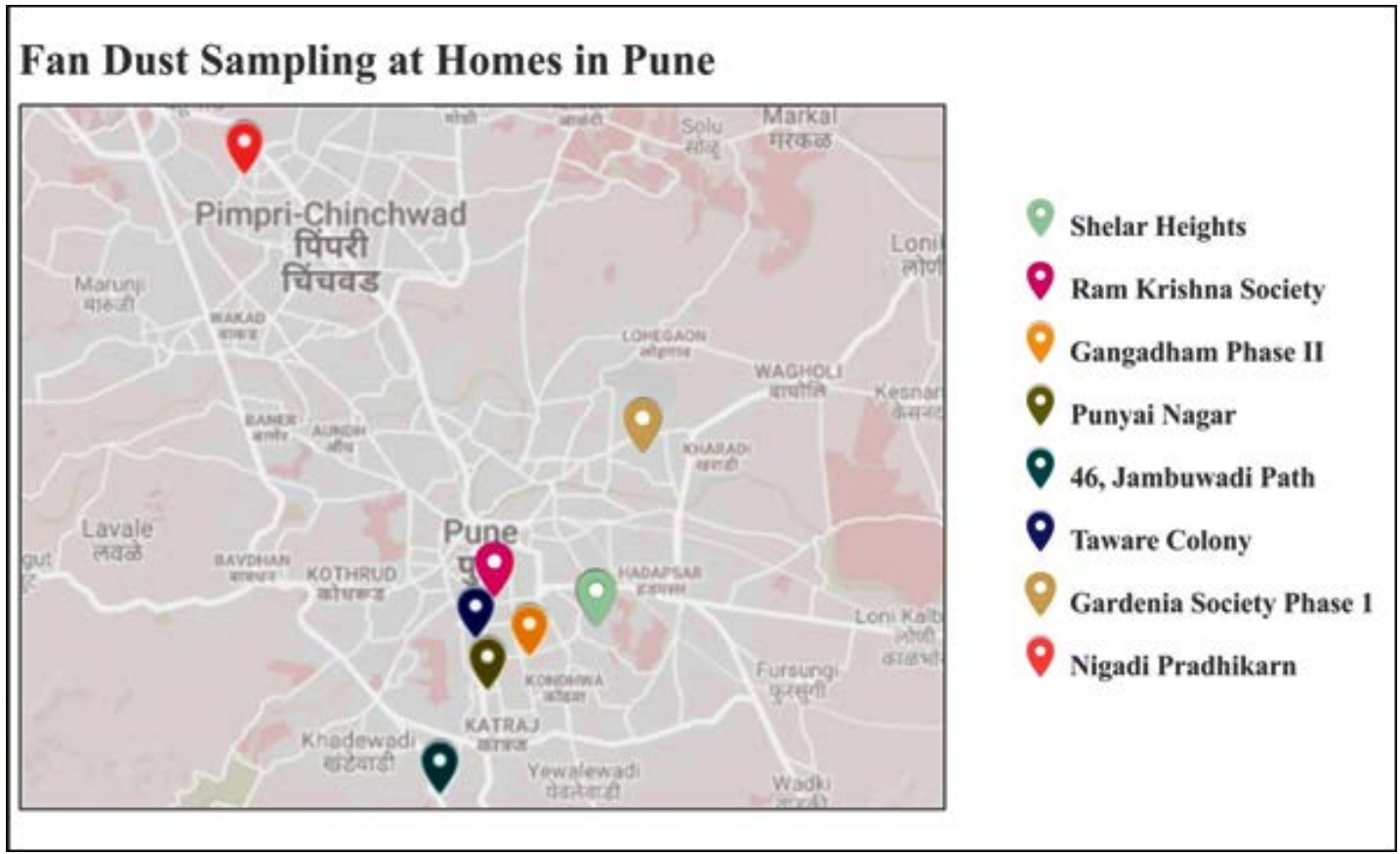

Fig. 2. Map of Pune Showing Fan Dust Sampling Spots 


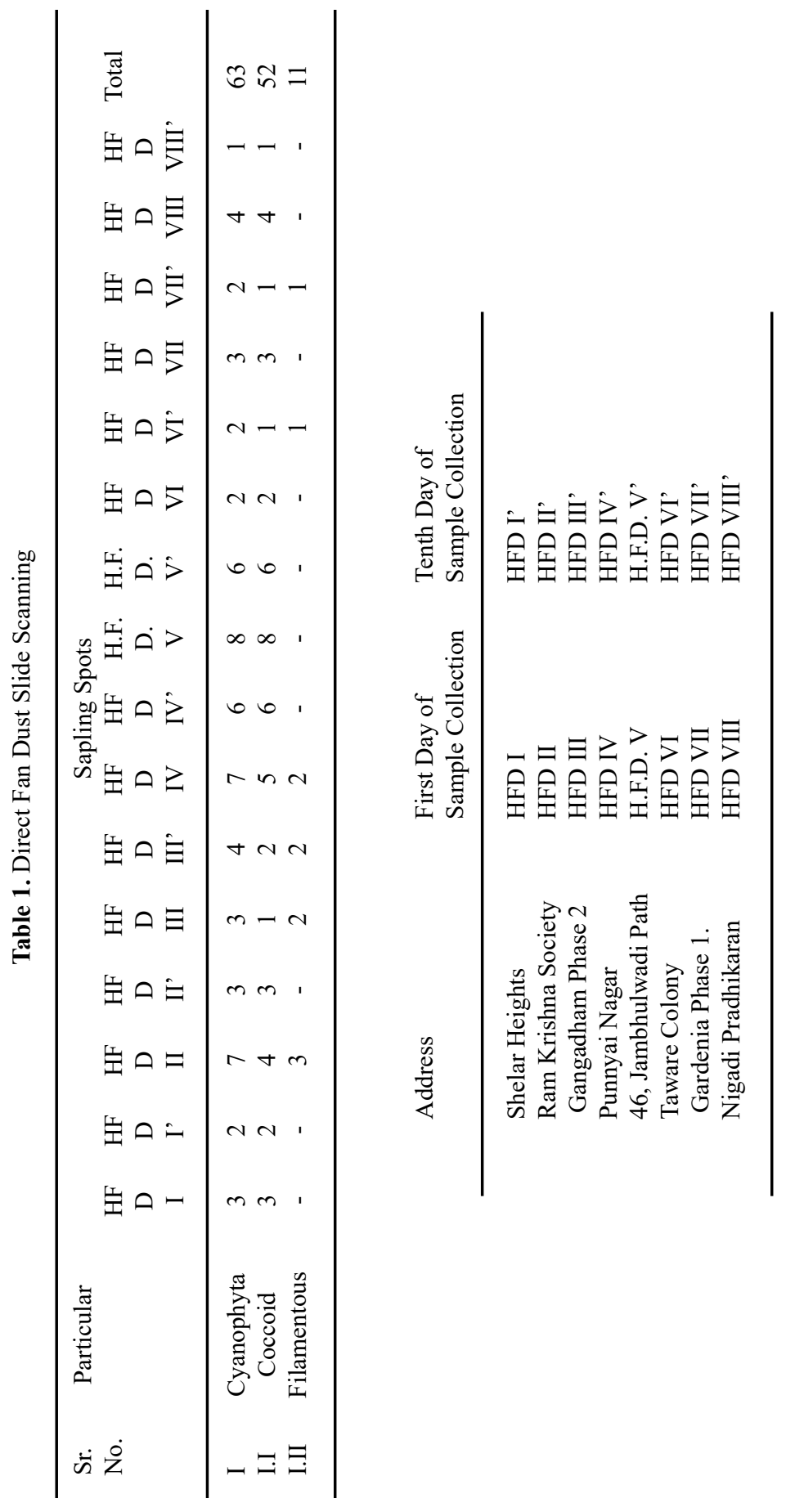




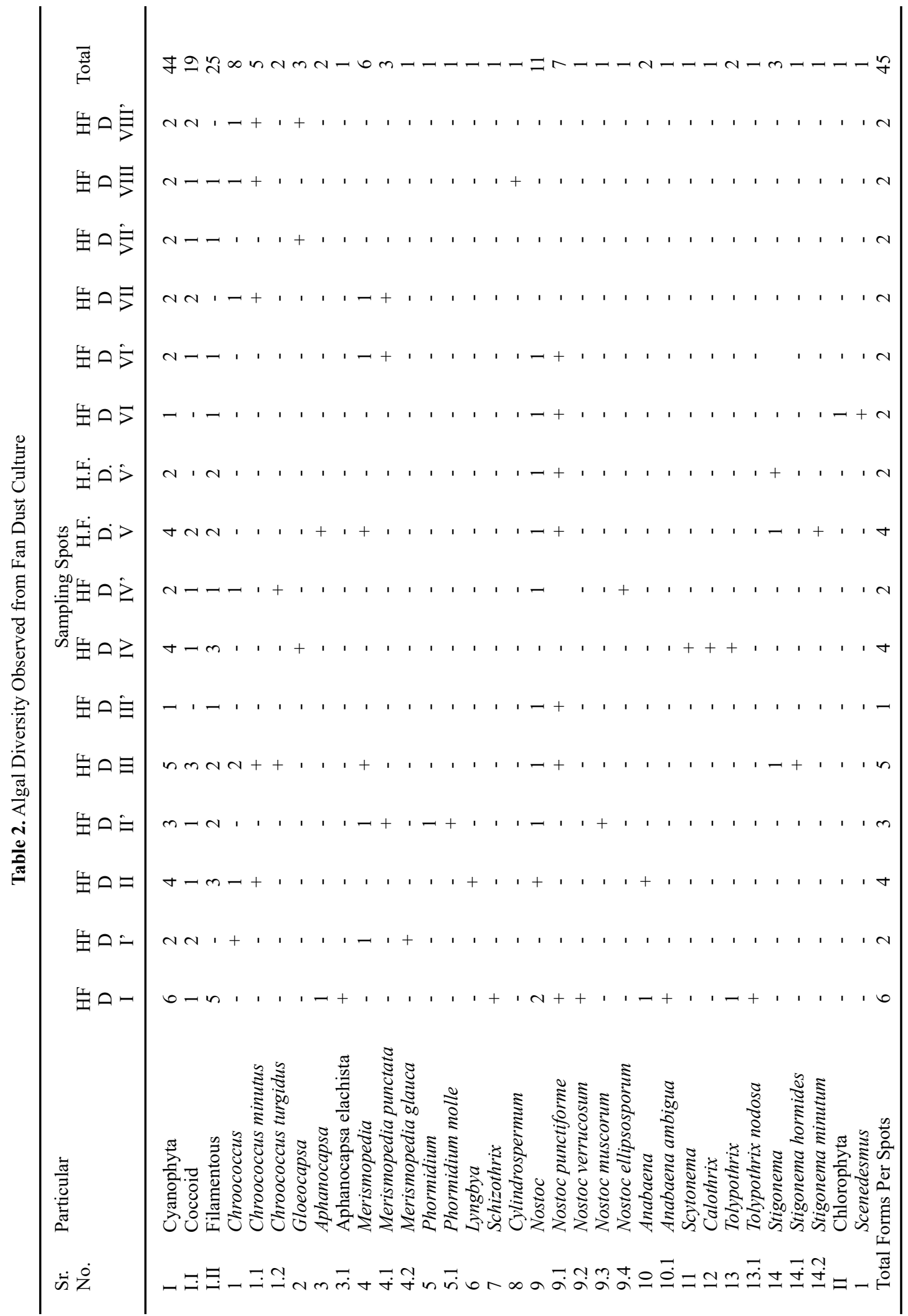


minutum recorded from (1) sample each. Anabaena was recorded from (2) samples, out of which one was identified up to species level as Anabaena ambigua. Tolypothrix was recorded from (2) samples. Phormidium recorded from (1) sample was identified as Phormidium molle while the rest of other genera like Lyngbya, Schizothrix, Cylindrospermum, Calothrix, and Scytonema were recorded from (1) sample each. Coccoid forms observed from culture show dominance of Chroococcus (8) with Chroococcus minutus recorded from (5) samples followed by Chroococcus turgidus, which was recorded from (2) samples each. It

\section{\% Occurrence of Coccoid Cyanophyta and Filamentous Cyanophyta from Direct Slide Scanning}

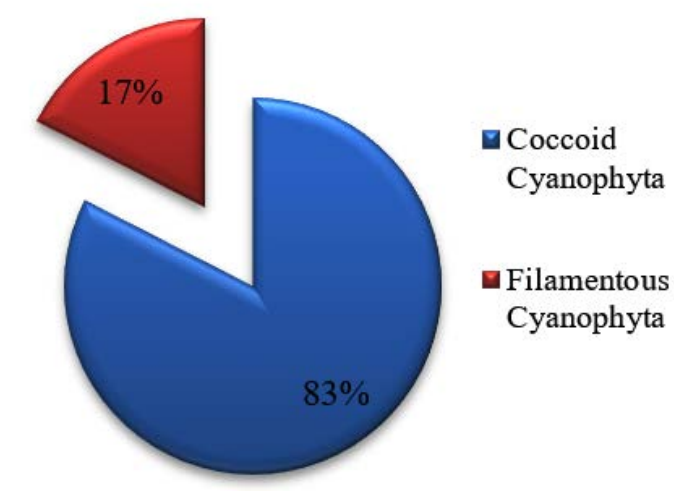

Graph I

Generic Diversity From Culture

11

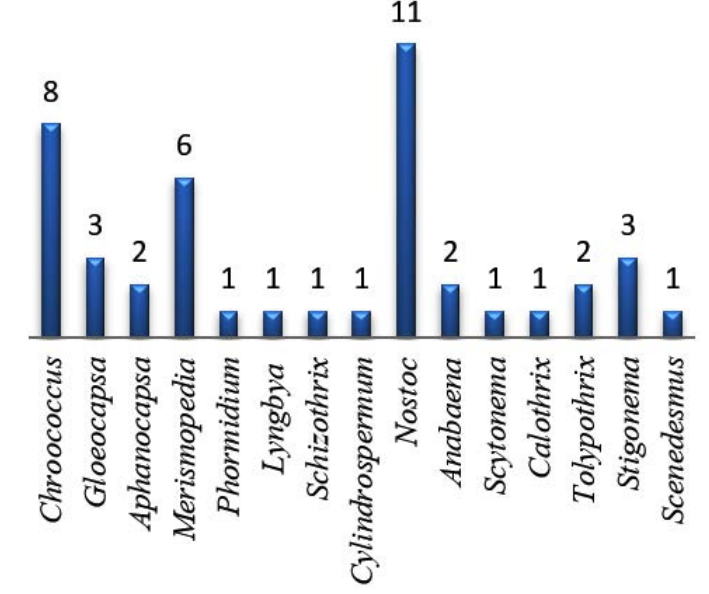

Graph III was followed by Merismopedia (6), out of which Merismopedia punctata was recorded from (3) samples while Merismopedia glauca was recorded from (2) samples each. Gloeocapsa was recorded from (3) samples, while Aphanocapsa was recorded from (2) samples. (Table 2, Graph III)

Variation among algal forms per spot in culture samples was observed. HFD I (6) shows maximum algal forms, followed by HFD III, where (5) algal forms were recorded.HFD II, HFD IV, and H.F.D. $V$ recorded (4) algal forms each. These cultures were obtained from fan dust samples collected on the first day of sampling.

The same spots on the tenth day show a significant drop in the algal count. HFD II' recorded (3) algal forms followed by HFD I', HFD IV', and

\section{$\%$ Occurrence of Coccoid Cyanophyta and Filamentous Cyanophyta from Culture Samples}
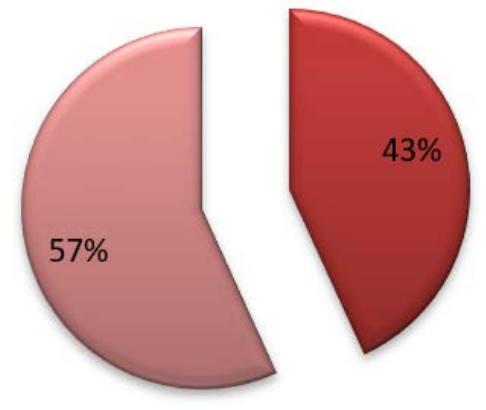

$\square$ Coccoid Cyanophyta

$\square$ Filamentous Cyanophyta
Total Aero-algal Forms Per Sampling

6

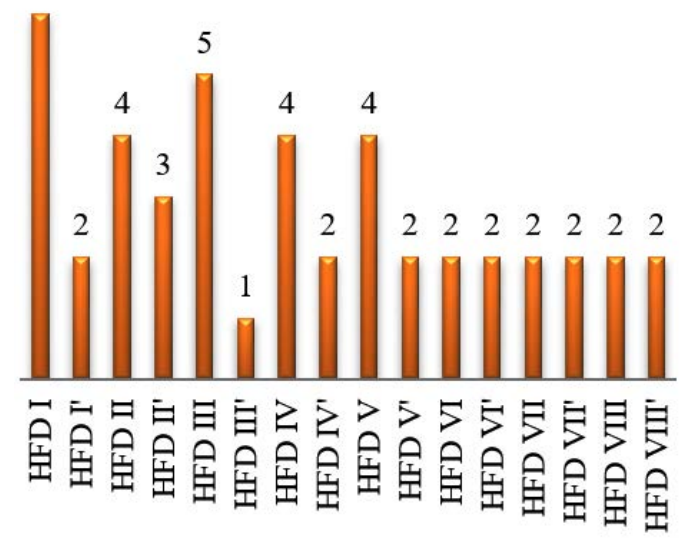

Graph IV 
HFD III' recorded (2) algal forms each. HFD III' shows the presence of a single form. Sampling spots like HFD VI, HFD VII and HFD VIII with (2) algal forms remained unchanged on both days of sampling (Graph IV).

Chrooccocus, Gloeocapsa, Lyngbya, Nostoc, and Stigonema were among the forms found on the first and tenth days of fan dust sampling, indicating that they were a common inhabitant of fan dust during the study and that the fan, as an aero sampler, was able to capture them, demonstrating its potency. Soil can play a key role in the formation of fan dust, as these genera were commonly isolated from soil Sathish C. et al. $(2020)^{36}$.

Indoor air sampling was carried out at Kaula Lumpur by W-L. Chu et al (2013) ${ }^{12}$ reported Phormidium angustissima as dominant species. A study carried out by Pandkar (2011) ${ }^{2}$ at Nagpur revealed the dominance of Cyanophyta with genera recorded like Phormidium, Chrooccocus, Gloeocapsa, Lyngbya, Calothrix, Merismopedia, and Scytonema. A similar study at Guhagar by Pandkar $(2017)^{32}$ shows the dominance of Cyanophyta with the presence of genera like Chroococcus, Nostoc, Phormidium, Microcoleus,

Microphotograph from Direct Fan Dust

Coccoid Forms (Cyanophyta)

Filamentous Forms (Cyanophyta)
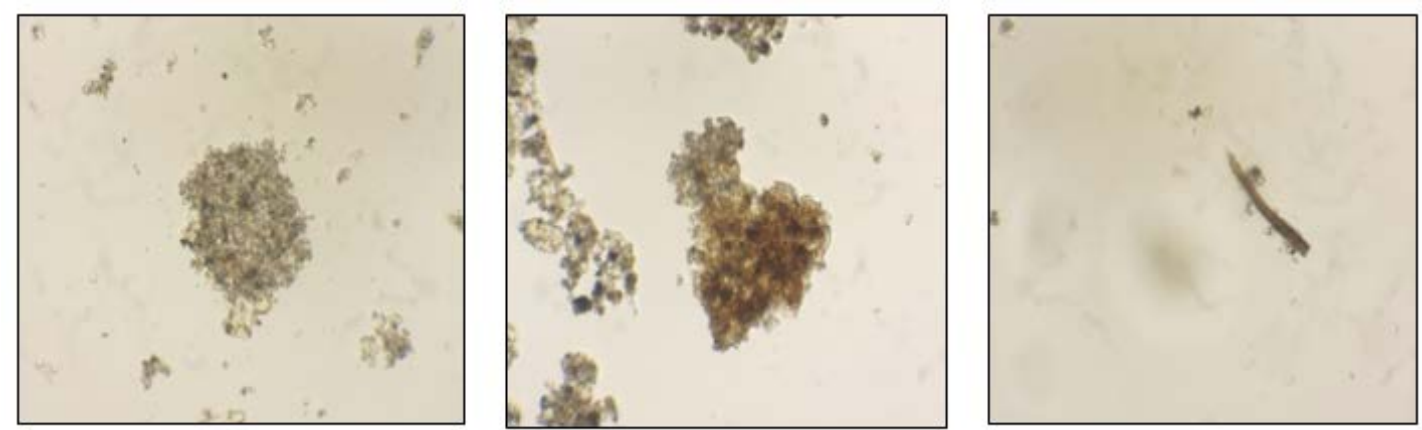

Microphotograph from Culture Sample

Coccoid Forms (Cyanophyta)

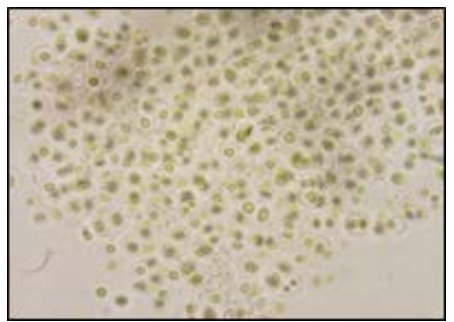

Chroococcus minutus (Kutz.) $\mathrm{Nag}$

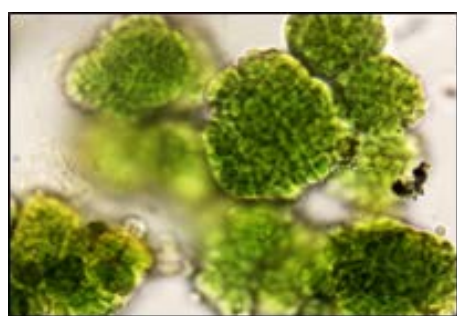

Merismopedia glauca (Ehrenb.)Nag

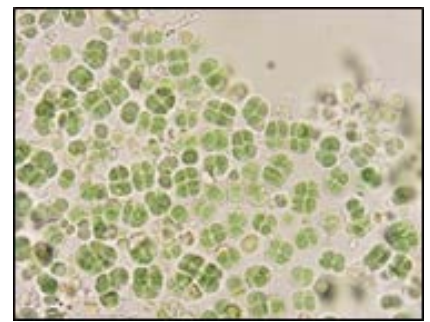

Gloeocapsa aeruginosa (Carm.)Kutz

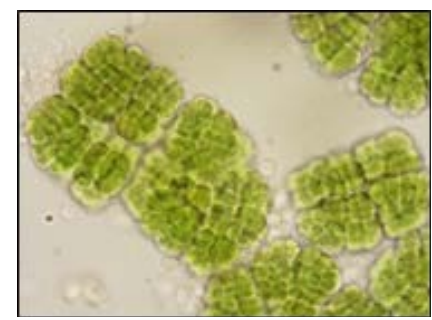

Merismopedia punctata Meyen

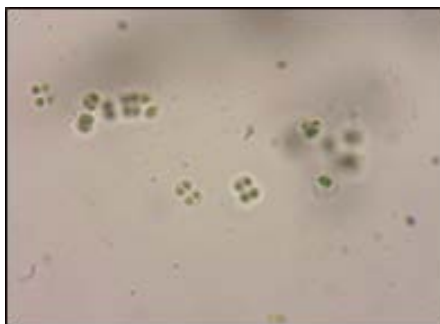

Gloeocapsa Sps. 
Filamentous Forms (Cyanophyta)

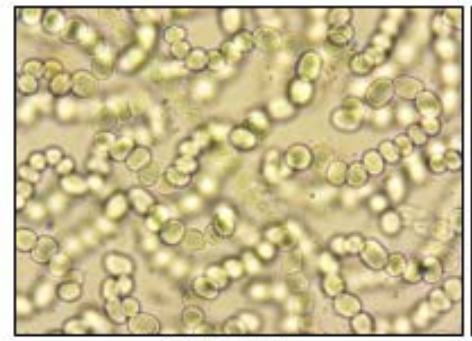

Nostoc Sps.

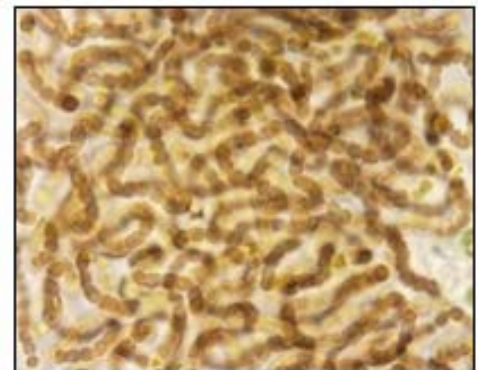

Nostoc verrucosum Vaucher ex Born. et Flah

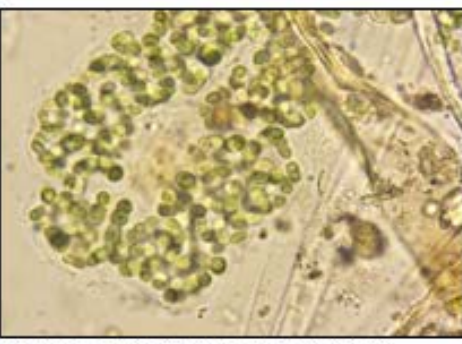

Nostoc punctiforme (Kutz.) Hariot

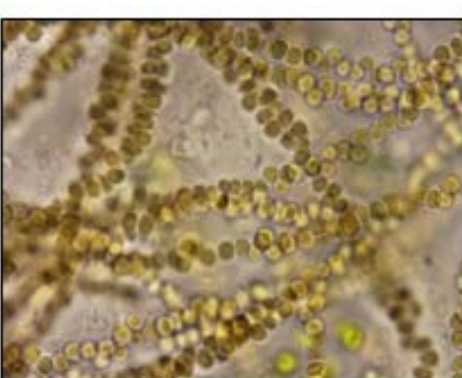

Anabaena ambigua Rao, C.B.

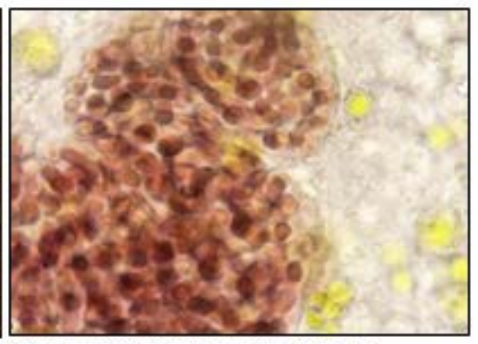

Nostoc punctiforme (Kutz.) Hariot

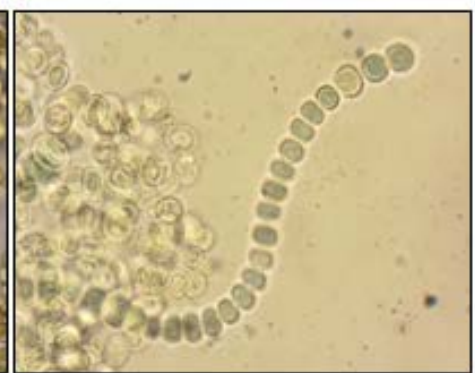

Anabaena Sps.

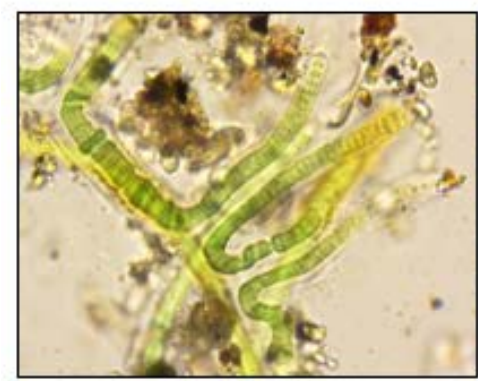

Scytonema Sps.

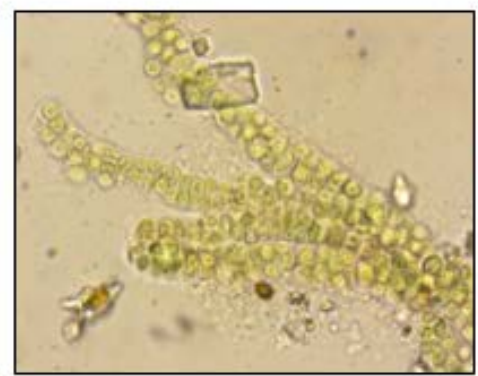

Stigonema minutum (Ag.)

Hassall ex Bomet Flah

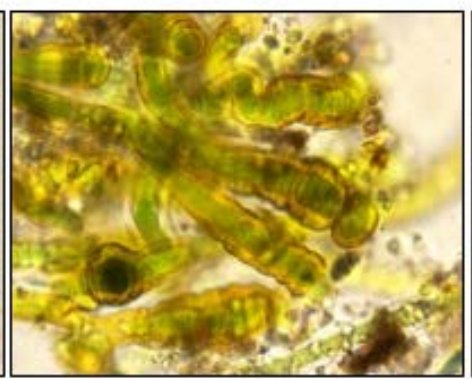

Calothrix Sps.

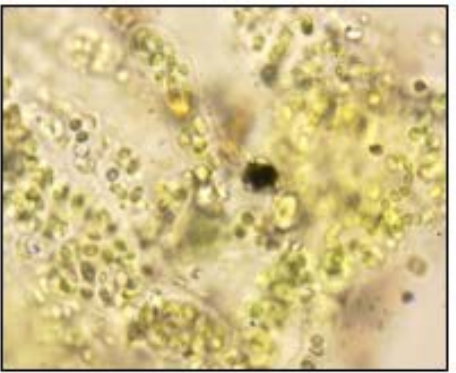

Stigonema hormides (Kutz.) Born. et Flah

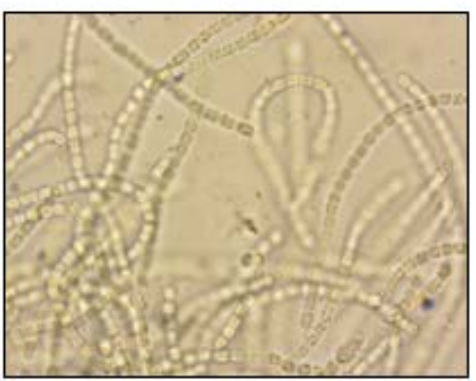

Cylindrospermum Sps.

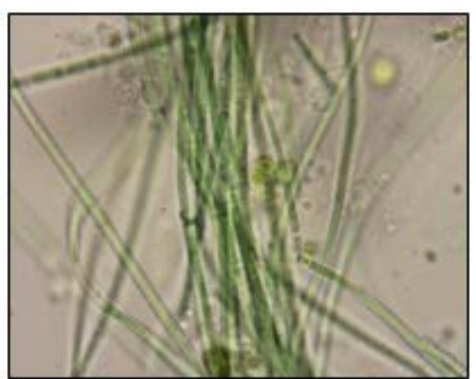

Phormidium molle (Kutz.) Gomont and Microcystis. Chougule et al. $(2016)^{28}$ reported the dominance of Cyanophyta in house dust samples with genera like Aphanothece, Gloeothece, Calothrix, Scytonema, and Chlorella. Similar results obtained in the present study indicate the ceiling fan's potential as a versatile aero sampler for qualitative study. On the contrary, researchers like R.S.Safferman (1970) $)^{37}$ and Jadhav et al. $(2021)^{38}$ observed dominance of Chlorophyta members like Chlorococccum and Chlorella in house dust. 
Cohen et al. (1952) ${ }^{39}$ reported dermatitis caused by coming in contact with blue-green alga. Louis Pilotto et al. (2004) $)^{40}$ studied cutaneous irritation by cyanobacteria. N.K.Sharma (2006) 41 investigated the potential allergenicity of Phormidium fragile and Nostoc muscorum and found that Nostoc muscorum to be more allergenic than Phormidium fragile. In another study carried out by N.K.Sharma $(2008)^{42}$ on mice by administrating crude extract of Nostoc muscorum to find its possible entry point to cause a toxic reaction in mice. N.Lang-Yona et al. (2018) ${ }^{43}$ on Nostoc sp. reveal its potency as an allergen. In the present study, aero-algal genera were recorded like Phormidium, Lyngbya, Cylindrospermum, Nostoc, Anabaena, and Scenedesmus (Genitsaris et al. 2011)44, Gloeocapsa and Schizothrix (Pandkar 2011,2011)2,30, Calothrix and Scytonema (Chougule et al. 2016) ${ }^{28}$, has been reported as allergenic. Species like Nostoc muscorum, Nostoc punctiforme and Phormidium molle encountered during the study were reported as allergenic by Jadhav et al. (2010)25 and Jawale et al. (2017)26.

Fan dust, a typical component of household dust that contains a number of allergenic components, appears to be a potential cause of human exposure and sensitisation to different algae, perhaps resulting in clinical allergy disorders. However, a more thorough investigation is needed because all houses reveal the existence of aero algal forms, which could be possible allergenic algal forms capable of causing allergic reactions in immunocompromised people.

\section{CONCLUSION}

A total of 108 algal species were discovered in 8 homes in and around Pune. There were 107 cyanophytes, showing that the Cyanophyta dominated the group. The existence of a thick mucilaginous coating around Cyanophyta members allowed them to endure desiccation by dryness, resulting in their supremacy. Sampling must be followed by culturing to see any latent spore forms. Gloeocapsa, Phormidium, Lyngbya, Schizothrix, Cylindrospermum, Nostoc, Anabaena, Scytonema, Calothrix, and Scenedesmus were among the allergenic aero-algae found during the study. Allergic species such as Nostoc muscorum, Nostoc punctiforme, and Phormidium molle were also discovered. However, such intramural allergenic algae represent significant health hazards, necessitating more investigation.

According to the results of the study, a ceiling fan may be employed as a cost-effective multifunctional aero sampler.

\section{ACKNOWLEDGMENT}

The authors are thankful to Principal Fergusson College (Autonomous) Pune, Savitribai Phule Pune University, and Head Department of Botany Fergusson College for granting permission to complete this work. The authors are also thankful to B.A.R.T.I. for providing financial assistance to the present investigation.

\section{Conflict of interests}

The authors declare that there is no conflict of interest regarding the publication of this paper.

\section{REFERENCES}

1. Ehrenberg. Dust showers and red rain. Chamber's Edinburgh Journal., 1852;17:432.

2. Pandkar J.T. Fan dust samples - A new approach to aero-phycological sampling. Biosci. Biotech. Res. Asia., 2011;8(2):795-799.

3. Luty T. E. An ecological study of the viable airborne algae of the Tucson and the Santa Catalina mountain areas. Arizona, 1964.

4. Fulton J. D and Mitchell R. B. Microorganisms of the upper atmosphere. Applied Microbiology., 1966;14(2):232-236.

5. Schlichting H. E. A preliminary study of the algae and protozoa in seafoam. Botanica Marina.,1971; XIV: 24-28.

6. Burge H. A, Solomon W. R, and Muilenberg L. M. Evaluation of indoor planting as allergen exposure sources. J.Allergy Clin. Immunol., 1982; 70(2):101-108.

7. Lee T. F and Eggleston P. M. Airborn algae and cyanobacteria. Grana.,1989;28: 63-66.

8. El-Gamal A. D. Aerophytic Cyanophyceae (cyanobacteria) from some Cairo District, Egypt. Pak.J.Biol.Sci.,2008;11(10):1293-1302.

9. Nuhu A. A and Ahmad S. Characterization of biotic and abiotic profiles of greenhouse evaporative cooling system fouling. Trop $J$ Pharm Res., 2008;7(3): 1043-1049.

10. Ambu S., Chu L. W, Mak W. J, Wong S. F, Chan L. L, and Wong S. T. Environmental health and building-related illnesses. IeJSME., 2008; 2(1): 
S11-S18.

11. Hui-Ping E. NG, Chu W. L and Ambu S. Occurrence of airborne algae within the township of Bukit Jalil in Kuala Lumpur, Malaysia. Grana., 2011;50: 217-227.

12. Chu W. L, Tneh S.Y and Ambu S. A survey of airborne algae and cyanobacteria within the indoor environment of an office building in Kuala Lumpur, Malaysia. Grana., 2013;52(3):207-220.

13. Tesson S. V. M, Skjoth C. A, Temkiv T. S and Londahl J. Airborne Microalgae: insight, opportunities, and challenges. Applied and Environmental Microbiology., 2016;82(7):19781991.

14. Fang Z, Guo W, Zhang J and Lou X. Influence of heat events on the composition of airborne bacterial communities in urban ecosystems. Int. J. Environ. Res. Public Health., 2018;15(2295): $1-13$.

15. Sharma N. K, Singh S and Rai A. K. Diversity and seasonal variation of viable algal particles in the atmosphere of a subtropical city in India. Environmental Research., 2006;102: 253-259.

16. Sharma N. K, Rai A. K and Singh S. Meteorological factors affecting the diversity of airborne algae in an urban atmosphere. Ecography., 2006; 29: 766-772.

17. Sharma N. K and Singh S. Differential aerosolisation of algal and cyanobacterial particles in the atmosphere. Indian J Microbial., 2010;50(4): 468-473.

18. Dubey S, Dixit A and Boswal M. V. Seasonal distribution of aero algal allergens in the wetlands of Kanpur. The Bioscan., 2010;3:673-680.

19. Verma S and Khan Z.H. Population dynamics of aero-algal flora of rural Kanpur. The Bioscan., 2012;7(4):723-725.

20. Seetharam D. S, Ramkrishna H, Kailash J.G and Prabhakar R. Allergenic aerospora from the spider webs of Sanjeevaiah Park in Hyderabad city, Telangana state. Poll Res., 2015;34(4):759769.

21. Seetharam D. S, Ramkrishna H, Prabhakar R and Kailash J. G. Aerobiological study from the spider webs of Pakhal wildlife sanctuary, Warangal district, Telangana state, India. The Bioscan., 2016;11(2):851-856.

22. Sharma N. K, Singh S, Rai A. K and Brown R. M. Airborne algae their present status and relevance. Journal of Phycology., 2006.

23. Sahu N and Tangutur A. D. Airborne algae: overview of the current status and its implications on the environment. Aerobiologia., 2014.

24. Pandkar J. T and Tarar J. L. Air borne algal pollutants from a vegetable and a fish market at Nagpur. The Botanique., 2010;14(1):22-27.
25. Jadhav M and Quazi S.M. Diversity of airborne algae in the atmosphere of Aurangabad. Bionano Frontier, 2010;3(2):287-289.

26. Jawale S. V and Jadhav M. J. Abundance of airborne algae in the atmosphere of Aurangabad city (M.S). Trends in Life Sciences.,2017;6(2):1-3.

27. Pandkar J. T. Preliminary study of allergenic algae of air at human breathing level from Nagpur. Biosci. Biotech. Res. Asia., 2011;8(1):159-164.

28. Chougule M. P and Andoji S. Y. Isolation and identification of house dust micro-algae from sangali district. RJLBPCS.,2016;1(5): 237-240.

29. Balkrishnan M. S and Gunale V. R. Cyanophycean air pollutants: a possible cause on inhalant allergy. Indian J. Air Pollut., 1980;3: 9-17.

30. Pandkar J. T. Presence of high algal diversity in Pune air. International Conference on Biodiversity and its Conservation.,2011;1-10.

31. Patil V. S and Patil S. R. Air dispersion of viable algae in the extramural environment of Pune. International Journal of Advanced Research., 2014;2(4):509-514.

32. Pandkar J. T. Report on aero-algal form from Konkan coastal area. Annals of Plant Sciences., 2017;6(11):1772-1774.

33. Desikachary T. V. Cyanophyta, I.C.A.R. monograph on algae, New Delhi.1959.

34. Prescott G. W. The fresh water algae. W.M.C. Brown Pub., Dubuque, Iowa. 1954.

35. Pandkar J. T, Kamble A. K, Hasnalkar S. P and Babar H. N Study of varied habitats and its effect on algal diversity from Fergusson College, Pune. Biosci. Biotech. Res. Asia., 2020;17(2): 235-245.

36. Satish C., Rekha C.R, Sahana C., Shrushti S. A qualitative investigation of airborne algae in government science college campus Bengaluru, India. IJSRBS., 2020;7(5):24-28.

37. Bernstein I.L., Safferman R.S. Viable algae in hose dust., Nature., 1970;227:851-852.

38. Jadhav M.J., Jawale S.V. House dust algae from Aurangabad city of Maharashtra., Plantae Scientia., 2021;4(3):160-162.

39. Sheldon G. C, Charles B. R and Wilkes B. Cutaneous sensitisation to blue green algae. The Journal of Allergy., 1953;452-457.

40. Pilotto L, Hobson P, Burch M. D, Ranmuthugala G, Attewell R and Weightman W. Acute skin irritant effects of cyanobacteria (blue-green algae) in healthy volunteers. Australian and New Zealand Journal of Public Health., 2004;28(3):220-224.

41. Sharma N. K and Rai A. K. Allergenicity of airborn cyanobacteria Phormidium fragile and Nostoc muscorum. Ecotoxicology and Environmental Safety.,2006;69:158-162.

42. Sharma N. K, Singh S and Rai A. K. Effect of 
Nostoc muscorum on the upper respiratory tract of mice. International Journal on Algae., 2008; 10(1):34-41.

43. Lang-Yona N, Kunert A. T, Vogel L, Kampf C. J, Bellinghausen I, Saloga J, Schink A, Ziegler K, Lucas K, Schuppan D, Poschl U, Weber B and Frohlich-Nowoisky J. Fresh water, marine and terrestrial cyanobacteria display distinct allergen characteristics. Science of the Total Environment.,2018;612:767-774.

44. Genitsaris S, Kormas K. A, and Gouni M. M. Airborne algae and cyanobacteria: occurrence and related health effects. Frontiers in Bioscience., 2011;1-16. 